\title{
Validating the utilisation of venous bicarbonate as a predictor of acute kidney injury in crush syndrome from sjambok injuries
}

\author{
D L Skinner, ${ }^{1} \mathrm{MB}$ ChB, MMed, FCS (SA), Cert Crit Care (SA); G L Laing, ${ }^{2,3}$ MB ChB, PhD, FCS (SA), Cert Trauma Surgery (SA); \\ J Bruce, ${ }^{2,3}$ MB ChB, FCS (SA); B Biccard, ${ }^{4}$ MB ChB, MMedSci, PhD, FCA (SA), FFARCSI; D J J Muckart, ${ }^{3}$ MB ChB, MMedSci, FRCS, \\ Cert Crit Care (SA) \\ ${ }^{1}$ Department of Anaesthesiology and Critical Care, School of Clinical Medicine, College of Health Sciences, Nelson R Mandela School of Medicine, \\ University of KwaZulu-Natal, Durban, South Africa \\ ${ }^{2}$ Pietermaritzburg Metropolitan Trauma Service, KwaZulu-Natal, South Africa \\ ${ }^{3}$ Department of General Surgery, School of Clinical Medicine, College of Health Sciences, Nelson R Mandela School of Medicine, University of \\ KwaZulu-Natal, Durban, South Africa \\ ${ }^{4}$ Department of Anaesthesia and Perioperative Medicine, Faculty of Health Sciences, University of Cape Town, South Africa
}

Corresponding author: D L Skinner (drdavidskinner@gmail.com)

\begin{abstract}
Background. Crush injury secondary to sjambok beatings is a well-described phenomenon in southern Africa. Owing to a number of factors, it can result in acute kidney injury (AKI). In 1992, Muckart et al. described a risk stratification system using venous bicarbonate (VB) that can be used in the management of these patients.

Objective. To validate this score in the modern era of AKI risk stratification.

Methods. A retrospective study was performed on a local trauma database from June 2010 to December 2012. All patients with crush injury from sjambok/blunt instrument beatings were included in the analysis. VB was compared with the Kidney Disease Improving Global Outcomes scoring system for AKI. Serum base excess (BE) and creatine kinase were also examined as biomarkers. The endpoints were the need for renal replacement therapy (RRT) and mortality.

Results. Three hundred and ten patients were included. The overall mortality rate was $1.9 \%, 14.8 \%$ of patients had AKI, and $3.9 \%$ required RRT. Both VB and BE performed well in RRT prediction, with areas under the receiver operating characteristic curve of 0.847 (95\% confidence interval (CI) $0.756-0.938 ; p<0.001)$ and $0.871(95 \%$ CI $0.795-0.947 ; p<0.001)$, respectively. The sensitivity and specificity of BE were $83.3 \%$ and $80.2 \%$ at an optimal cut-point of $-7.25 \mathrm{mmol} / \mathrm{L}$, while those of $\mathrm{VB}$ were $83.3 \%$ and $79.5 \%$ at an optimal cut-point of $18.85 \mathrm{mmol} / \mathrm{L}$. VB was significantly different across the AKI risk groups $(p<0.001)$, in keeping with the original Muckart risk stratification system.

Conclusion. The risk stratification score using VB is valid and should continue to be used as a tool in the management of patients with sjambok injuries. BE performs well in predicting the need for RRT, with a value of $<-7.25 \mathrm{mmol} / \mathrm{L}$ indicating severe injury.
\end{abstract}

S Afr Med J 2017;107(5):446-450. DOI:10.7196/SAMJ.2017.v107i5.12213

Crush injury secondary to sjambok beatings is a well-described phenomenon in southern Africa. The sjambok, a type of traditional stiff whip normally made out of animal leather or plastic, is often used to inflict punishment in 'community justice' events. Damage to underlying muscle results in the release of myoglobin. Subsequent myoglobin deposition in the kidneys, combined with hypovolaemia from fluid sequestration into the damaged soft tissues and renal tubular cast formation, can result in acute kidney injury (AKI).

Risk stratification for prognostication in AKI has progressed from various consensus definitions, from the Risk, Injury, Failure, Loss and End-stage renal disease (RIFLE ${ }^{[1]}$ to the Acute Kidney Injury Network (AKIN) $)^{[2]}$ and now the Kidney Disease Improving Global Outcomes (KDIGO) scoring system. ${ }^{[3]}$ These systems use urine output, the glomerular filtration rate or serum creatinine for risk stratification.

Previous studies by Muckart et al. ${ }^{[4,5]}$ described AKI following sjambok injuries and subsequently examined risk stratification in a cohort of 64 patients who presented to an acute care surgical unit, using serum venous bicarbonate (VB), serum electrolytes and urine pigment as biomarkers to predict severity of injury. Other studies have examined the use of serum creatine kinase $(\mathrm{CK})$. $^{[6,7]}$

\section{Objective}

To examine the use of VB in the modern era of risk stratification of AKI using the KDIGO scoring system and compare initial serum VB with the need for renal replacement therapy (RRT).

\section{Methods}

The primary objective was to compare the risk prediction score using VB for crush syndrome (as developed by Muckart et al. ${ }^{[5]}$ ) with the KDIGO scoring system for AKI in a cohort of patients presenting to a surgical unit after sjambok or punishment beatings. The endpoints were the need for RRT and mortality. The secondary objectives were to evaluate the utility of serum base excess (BE) and CK in predicting the need for RRT.

Data were collected from a database maintained by the Pietermaritzburg Metropolitan Trauma Service from June 2010 to December 2012. This database included patient admissions from Grey's and Edendale hospitals in KwaZulu-Natal Province, South Africa (SA). Ethics application was made to the University of KwaZulu-Natal Biomedical Research Ethics Committee prior to establishment of the database (ref. no. BCA221/13), and patient confidentiality was maintained. 
All patients in the database with a diagnosis of sjambok injury or crush injury were included in the analysis. Patients with crush injury and

\begin{tabular}{llll}
$\begin{array}{l}\text { Table 1. Severity } \\
\text { Muckart } \text { et } \text { al }^{[5]}\end{array}$ & $\begin{array}{l}\text { Venous } \\
\text { bicarbonate } \\
(\mathbf{m m o l} / \mathbf{L})\end{array}$ & $\begin{array}{l}\text { Serum } \\
\text { electrolytes }\end{array}$ & Urine pigment \\
\hline $\begin{array}{l}\text { Injury } \\
\text { severity }\end{array}$ & $>20$ & Normal & Negative \\
\hline Minimal & $>20$ & Normal & Positive \\
Mild & $17-20$ & Normal & Positive \\
Moderate & $17-20$ & Abnormal & Positive \\
Major & $<17$ & Abnormal & Positive \\
Massive & & &
\end{tabular}

\begin{tabular}{lll} 
Table 2. KDIGO risk stratification for AKI & \\
\hline KDIGO & Serum creatinine & Urine output \\
\hline Stage 1 & $\uparrow$ in serum creatinine to $\geq 26.5$ & $<0.5 \mathrm{~mL} / \mathrm{kg} / \mathrm{h}$ \\
& $\begin{array}{l}\mu \text { mol} / \mathrm{L} \text { or increase to } \geq 150-199 \% \\
\text { from baseline }\end{array}$ & for $\geq 6 \mathrm{~h}$ \\
& $\uparrow$ in serum creatinine to $200-$ & $<0.5 \mathrm{~mL} / \mathrm{kg} / \mathrm{h}$ \\
Stage 2 & $299 \%(>2-2.9$-fold) from baseline & $\geq 12 \mathrm{~h}$ \\
& $\uparrow$ in serum creatinine to $\geq 300 \%$ & $<0.3 \mathrm{~mL} / \mathrm{kg} / \mathrm{h}$ \\
Stage 3 & $(\geq 3$-fold) from baseline or & $\geq 24 \mathrm{~h}$ or anuria \\
& Serum creatinine $>353.6 \mu \mathrm{mol} / \mathrm{L}$ & $\geq 12 \mathrm{~h}$ \\
& or & \\
& Initiation of RRT
\end{tabular}

Table 3. Demographics and outcomes of patients admitted with sjambok injuries

\begin{tabular}{lllll}
\hline & $\begin{array}{l}\text { All patients } \\
(\boldsymbol{N = 3 1 0})\end{array}$ & $\begin{array}{l}\text { No AKI } \\
(\boldsymbol{n}=\mathbf{2 6 4})\end{array}$ & AKI $(\boldsymbol{n = 4 6 )})$ & $\boldsymbol{p}$-value \\
\hline Male, $n(\%)$ & $258(81.9)$ & $220(83.3)$ & $35(14.8)$ & 0.235 \\
$\begin{array}{l}\text { Age }(\mathrm{yr}), \text { mean } \\
(\mathrm{SD})\end{array}$ & $27.0(9.8)$ & $26.4(8.9)$ & $30.6(13.2)$ & $<0.001$ \\
Mortality, $n(\%)$ & $6(1.9)$ & $1(0.4)$ & $4(8.7)$ & 0.002 \\
RRT, $n(\%)$ & $12(3.9)$ & $0(0)$ & $12(26.1)$ & $<0.001$
\end{tabular}

complex multisystem trauma were excluded from the study. Patient demographics were extracted, along with the admission blood results. Urinary pigment was checked by either a urinary dipstick reacting to haemoglobin or formal urinary myoglobin measurement. RRT was either peritoneal dialysis or haemodialysis, as resources dictated.

The previously validated score of risk stratification as per the original article by Muckart et al. ${ }^{[5]}$ involved the use of urine pigment, $\mathrm{VB}$ and serum electrolytes (Table 1).

We planned to assess the validity of $\mathrm{VB}$ as proposed in the original article $^{[5]}$ by comparing the three groups of $\mathrm{VB}$, namely $>20 \mathrm{mmol} / \mathrm{L}$, $17-20 \mathrm{mmol} / \mathrm{L}$ and $<17 \mathrm{mmol} / \mathrm{L}$. The injury severity of 'minimal' was omitted, and we did not examine urine pigment or serum electrolytes as risk-stratifying biomarkers.

AKI was diagnosed and staged via the highest serum creatinine measurement as per the KDIGO system (Table 2). ${ }^{[3]}$ As no patients were admitted with a known baseline creatinine level, the Modification of Disease in Renal Diet equation was used to calculate an assumed baseline (using age, sex and race), as per the KDIGO recommendations. ${ }^{[3]}$

\section{Statistical analysis}

Continuous data were reported as means and standard deviations (SDs) or medians and interquartile ranges (IQRs), as appropriate. The $\chi^{2}$ test with continuity correction was used for categorical data, and Student's $t$-test or the Mann-Whitney $U$-test for continuous data where appropriate.

Receiver operating characteristic (ROC) curves were constructed for $\mathrm{VB}, \mathrm{CK}$ and $\mathrm{BE}$ to examine their sensitivity and specificity $\mathrm{v}$. the need for RRT. The area under the curve (AUC), 95\% confidence intervals (CIs) and optimal cut-points were reported for all three biomarkers.

All $p$-values were reported to three decimal places, and statistical significance was defined as a two-sided $p$-value $<0.05$. All data analyses were performed using SPSS 24.0 for Macintosh (IBM Corp., USA).

\section{Results}

Three hundred and ten patients were admitted to the surgical units with a crush injury from sjambok or blunt instrument beatings. The majority were male $(83.3 \%)$ and young (mean (SD) age 27 (9.8)

Table 4. Admission serum biochemical values of patients presenting with sjambok injuries*

\begin{tabular}{|c|c|c|c|c|}
\hline & All patients $(N=310)$ & No AKI $(n=264)$ & AKI $(n=46)$ & $p$-value \\
\hline pH, median (IQR) & $7.36(7.30-7.39)$ & $7.36(7.31-7.40)$ & $7.30(7.21-7.37)$ & 0.001 \\
\hline Lactate (mmol/L), median (IQR) & $3.1(1.8-4.5)$ & $3.1(1.7-4.3)$ & $3.8(1.9-8.0)$ & 0.114 \\
\hline $\mathrm{PaCO}_{2}(\mathrm{kPa})$, median $(\mathrm{IQR})$ & $5.2(4.7-5.9)$ & $5.3(4.7-5.9)$ & $5.1(3.9-5.6)$ & 0.027 \\
\hline Bicarbonate (mmol/L), median (IQR) & $21.4(19.0-24.0)$ & $22.0(20.0-24.0)$ & $16.8(14.0-20.0)$ & $<0.001$ \\
\hline $\mathrm{BE}(\mathrm{mmol} / \mathrm{L})$, median IQR) & $-3.9(-7.0--1.6)$ & $-3.5(-6.4--1.3)$ & $-10.2(-12.6--5.7)$ & $<0.001$ \\
\hline $\mathrm{Hb}(\mathrm{g} / \mathrm{dL})$, median (IQR) & $13.4(11.3-14.7)$ & $13.6(12.2-13.9)$ & $10.4(8.1-13.7)$ & $<0.001$ \\
\hline Sodium (mmol/L), median (IQR) & $138(135-140)$ & $138(135-140)$ & $135(133-138)$ & $<0.001$ \\
\hline Potassium (mmol/L), median (IQR) & $4.1(3.8-4.5)$ & $4.1(3.8-4.4)$ & $4.3(3.9-5.0)$ & 0.006 \\
\hline Chloride (mmol/L), median (IQR) & $106(102-108)$ & $106(103-108)$ & $106(100-109)$ & 0.653 \\
\hline Urea (mmol/L), median (IQR) & $4.1(3.1-5.8)$ & $3.9(3.9-5.0)$ & $9.3(5.8-20.7)$ & $<0.001$ \\
\hline Creatinine $(\mu \mathrm{mol} / \mathrm{L})$, median (IQR) & $83(70-110)$ & $81(68-93)$ & $196(153-423)$ & $<0.001$ \\
\hline Corrected calcium (mmol/L), median (IQR) & $2.28(2.18-2.34)$ & $2.28(2.20-2.34)$ & $2.18(2.06-2.29)$ & 0.011 \\
\hline Magnesium (mmol/L), median (IQR) & $0.81(0.71-0.91)$ & $0.81(0.73-0.90)$ & $0.76(0.69-0.91)$ & 0.692 \\
\hline Phosphate (mmol/L), median (IQR) & $1.18(0.98-1.49)$ & $1.15(0.93-1.46)$ & $1.48(1.17-1.85)$ & 0.001 \\
\hline CK (U/L), median (IQR) & $1777(602-3981)$ & $1669(595-3207)$ & $3527(961-7534)$ & 0.015 \\
\hline Urinary pigment present, $n(\%)$ & $186(60.0)$ & $150(56.8)$ & $36(78.3)$ & 0.010 \\
\hline
\end{tabular}

$\mathrm{PaCO}_{2}=$ partial pressure of arterial carbon dioxide; $\mathrm{Hb}=$ haemoglobin.
${ }^{*} \mathrm{Data}$ incomplete for $\mathrm{CK}(52.9 \%$ missing), phosphate $(52.3 \%)$, calcium (59.7\%) and magnesium (51.9\%), as these are not considered routine screening tests in patients with crush injury. 


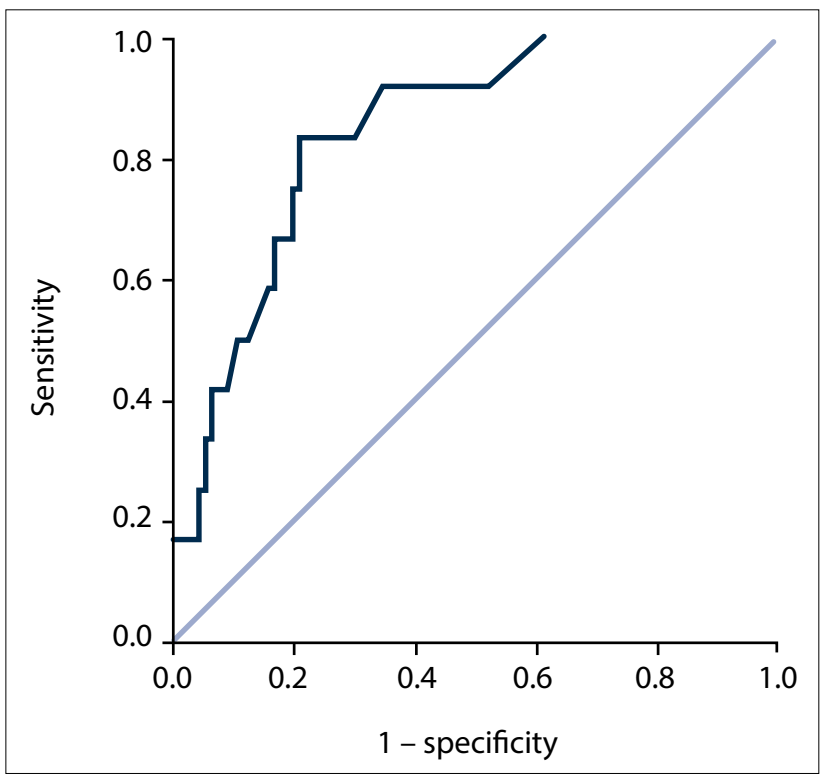

Fig. 1. VB v. RRT receiver operator characteristic curve. Diagonal segments are produced by ties.

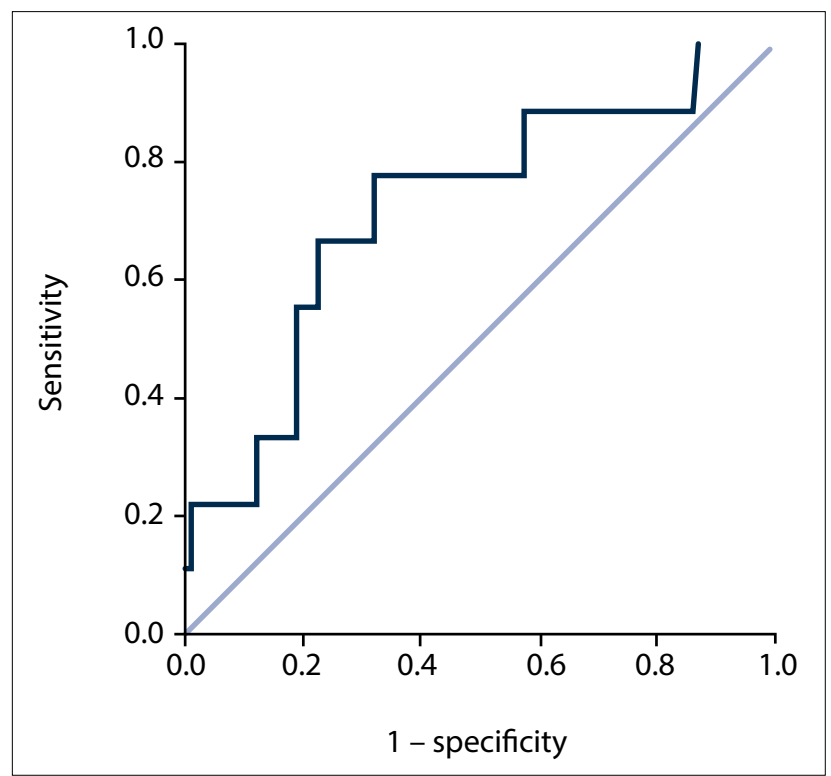

Fig. 2. CK v. RRT receiver operator characteristic curve. Diagonal segments are produced by ties.

Table 5. Performance of serum biomarkers for predicting the need for RRT

\begin{tabular}{llll}
\hline & Optimal cut-point & Sensitivity, \% & Specificity, \% \\
\hline BE & $-7.25 \mathrm{mmol} / \mathrm{L}$ & 83.3 & 80.2 \\
$\mathrm{VB}$ & $18.85 \mathrm{mmol} / \mathrm{L}$ & 83.3 & 79.5 \\
$\mathrm{CK}$ & $2791 \mathrm{mmol} / \mathrm{L}$ & 77.8 & 67.9
\end{tabular}

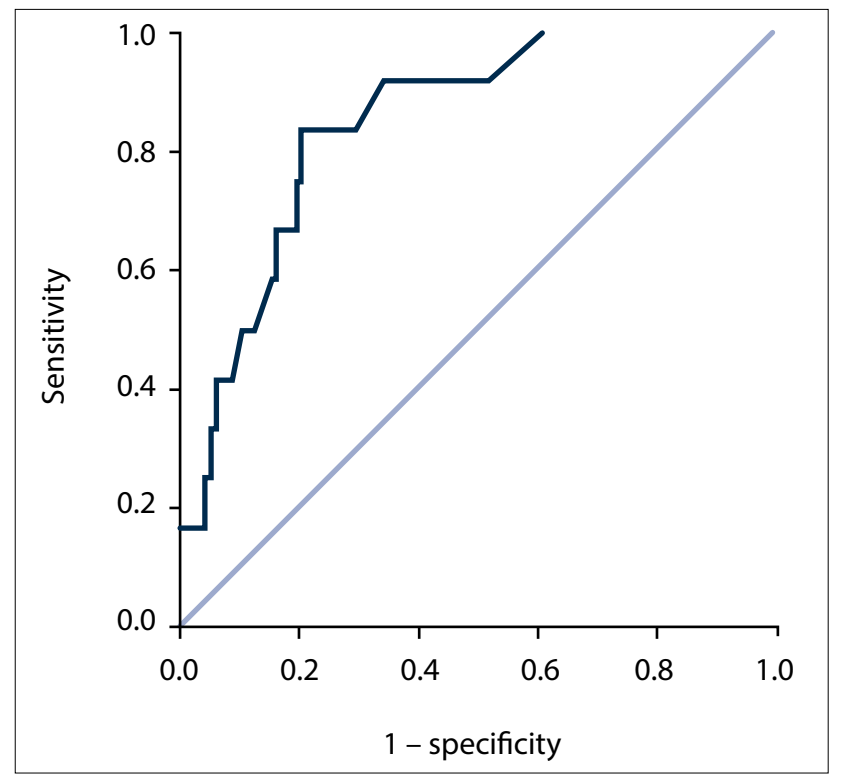

Fig. 3. BE v. RRT receiver operator characteristic curve. Diagonal segments are produced by ties.

years). There was a low mortality rate of $1.9 \%$ ( $n=6$ patients). Forty-six patients (14.8\%) were diagnosed with AKI and 12 (3.9\%) required RRT (Table 3). The results of biochemical investigations on admission are set out in Table 4 .

Of patients who presented with AKI, 18 had grade 1, 2 grade 2 and 26 grade 3 AKI. Owing to the small number of patients with grade 2 AKI, a post hoc decision was taken to combine this group with the grade 3 AKI group for the purposes of analysis. These groups were reported as no AKI, low-grade AKI (KDIGO stage 1) and high-grade AKI (KDIGO stages 2 and 3).

Serum CK levels were available for only 149 patients in the cohort, with a higher serum CK level in patients who developed AKI (median $3527 \mathrm{U} / \mathrm{L}$ ) (IQR 961 - 7 925)) than in those who did not (1 $777 \mathrm{U} / \mathrm{L}$ $(\mathrm{IQR} 602-3981))(p=0.015)$. Urinary pigment was present in a total of 186 patients $(60.0 \%)$, and in $36(78.3 \%)$ of those who developed AKI $(p=0.010)$.

VB had an AUC for RRT of 0.847 (95\% CI $0.756-0.938 ; p<0.001$ ) (Fig. 1), CK an AUC of 0.722 (95\% CI $0.544-0.900 ; p=0.026$ ) (Fig. 2) and BE an AUC of 0.871 (95\% CI $0.795-0.947$; $p<0.001$ ) (Fig. 3). Table 5 indicates the optimal cut-points, sensitivity and specificity of the ROC curves for the three serum biomarkers.

Patients who received RRT had significantly lower VB than those who did not (16.5 mmol/L (IQR 13.4 - 18.6) v. $21.6 \mathrm{mmol} / \mathrm{L}$ (IQR 19.2 - 24.0) $(p<0.001))$. The median highest serum creatinine level in patients who received RRT was $358 \mu \mathrm{mol} / \mathrm{L}$ (IQR 224 - 603), and the median urea level was $18.1 \mathrm{mmol} / \mathrm{L}$ (IQR $8.9-22.8$ ).

To validate the score developed by Muckart et al., ${ }^{[5]}$ patients were classified as mild, moderate or severe according to their VB only. Urine pigment and serum electrolytes were not included in the analysis. The serum creatinine and BE were significantly different

Table 6. Muckart score applied to the sjambok patient cohort $(N=310)$

\begin{tabular}{|c|c|c|c|c|}
\hline & $\begin{array}{l}\text { Mild (VB }>20 \mathrm{mmol} / \mathrm{L} \text {, } \\
n=192)\end{array}$ & $\begin{array}{l}\text { Moderate (VB } 17 \text { - } 20 \\
\mathrm{mmol} / \mathrm{L}, n=74)\end{array}$ & $\begin{array}{l}\text { Severe }(\mathrm{VB}<17 \mathrm{mmol} / \mathrm{L} \text {, } \\
n=44)\end{array}$ & $p$-value \\
\hline VB (mmol/L), median (IQR) & $23.0(21.9-24.7)$ & $19.1(18.0-20.0)$ & $14.3(13.0-16.0)$ & \\
\hline Serum creatinine $(\mu \mathrm{mol} / \mathrm{L})$, median $(\mathrm{IQR})$ & $81(69-93)$ & $84(74-127)$ & $162(103-557)$ & $<0.001$ \\
\hline $\mathrm{BE}(\mathrm{mmol} / \mathrm{L})$, median $(\mathrm{IQR})$ & $-2.2(-3.9--0.3)$ & $-6.5(-7.4--5.3)$ & $-12.1(-14.2--10.8)$ & $<0.001$ \\
\hline CK (mmol/L), median (IQR) & $1738(602-3207)$ & $1721(708-5592)$ & $3991(671-7543)$ & 0.204 \\
\hline
\end{tabular}


Table 7. KDIGO grading of all patients admitted with sjambok injuries $(N=310)$

\begin{tabular}{lllll}
\hline & No AKI $(\boldsymbol{n}=\mathbf{2 6 4})$ & Low-grade AKI $(\boldsymbol{n}=\mathbf{1 8})$ & High-grade AKI $(\boldsymbol{n}=\mathbf{2 8})$ & $\boldsymbol{p}$-value \\
\hline Serum creatinine $(\mu \mathrm{mol} / \mathrm{L})$, median $(\mathrm{IQR})$ & $81(68-93)$ & $167(153-182)$ & $351(195-487)$ & \\
VB $(\mathrm{mmol} / \mathrm{L})$, median $(\mathrm{IQR})$ & $22.0(20.0-24.0)$ & $17.0(15.0-21.0)$ & $16.5(13.8-19.2)$ & $<0.001$ \\
$\mathrm{BE}(\mathrm{mmol} / \mathrm{L})$, median $(\mathrm{IQR})$ & $-3.5(-6.4--1.3)$ & $-7.7(-13.4--4.0)$ & $-10.5(-12.6--7.2)$ & $<0.001$ \\
$\mathrm{CK}(\mathrm{mmol} / \mathrm{L})$, median $(\mathrm{IQR})$ & $1669(595-3207)$ & $3279(961-5594)$ & $3607(998-9735)$ & 0.052 \\
Low-grade AKI = KDIGO stage 1; high-grade AKI = KDIGO stages 2 and 3. & & &
\end{tabular}

across the three groups $(p<0.001)$, while CK was not significantly different $(p=0.204)$ (Table 6). Patients were also classified according to their KDIGO staging, and $\mathrm{VB}$ and $\mathrm{BE}$ remained significant $(p<0.001)$ while CK did not $(p=0.052)$ (Table 7$)$.

\section{Discussion}

This study confirms that VB remains a valid risk stratification tool in the management of patients at risk of AKI from crush injury. We have also shown that BE performs well as a biomarker for prediction of the need for RRT. Although CK is associated with the need for RRT, its performance is poorer than that of $\mathrm{VB}$ or $\mathrm{BE}$, and importantly, the CK level does not discriminate between low-grade and high-grade AKI. This therefore precludes the use of $\mathrm{CK}$ as a risk stratification tool for AKI following crush injury. Other authors have reported similar findings. ${ }^{[7-9]}$ Serum CK may be useful for the diagnosis of crush injury, rather than for risk stratification.

The mortality rate in our study was low (8.7\%). In our previous study examining AKI in critically ill patients, ${ }^{[10]}$ we noted a low mortality rate among critically ill patients with sjambok injuries (23\%), albeit in a small cohort of 13 patients. These findings contrast with other forms of trauma-associated AKI, where authors have reported mortality rates ranging from $28 \%$ to $100 \% .{ }^{[1-13]}$ Other studies examining mortality from all causes of rhabdomyolysis report rates of $5-24 \% \cdot{ }^{[6,8,14]}$

\section{Study strengths and limitations}

The strength of this study is that it examined a large, homogeneous population group over a 2-year period. Follow-up was complete to patient discharge. Although this study was performed in surgical units in KwaZulu-Natal, we believe that our findings are applicable to patients with crush syndrome in other surgical and emergency medicine units across SA.

There are some limitations to this study. There were no data available regarding the type, timing and volume of fluid administration prior to the serum samples being drawn, which could potentially have altered the biochemistry results. The period of time between the injury and presentation to a health facility was also unknown. Study data were also incomplete for serum CK (52.9\% missing), phosphate (52.3\%), calcium (59.7\%) and magnesium (51.9\%), as these are not considered routine screening tests in patients with crush injury.

Indications for RRT, types of RRT and triggers for RRT were not standardised in this study. This may have led to variability in the prescription and use of RRT.

\section{Recommendations}

We recommend that clinicians involved in the care of patients with crush injury from sjambok beating adopt the system we propose of early risk stratification using the initial VB, without the need for urine dipstick analysis or serum electrolyte analysis, based on the VB categories shown in Table 6.

In our resource-constrained environment, other renal biomarkers, such as urinary neutrophil gelatinase-associated lipocalin/cystatin C or kidney injury molecule 1, are currently too expensive to be used routinely. VB is a cost-effective tool for risk stratification in this setting.

We also recommend that patients presenting with a $\mathrm{BE}<-7.25$ $\mathrm{mmol} / \mathrm{L}$ in combination with a $\mathrm{VB}$ of $<17 \mathrm{mmol} / \mathrm{L}$ be managed in a healthcare facility that has access to adequate monitoring of renal function and access to RRT, as these patients have a high risk of needing RRT. Rapid access to RRT is lifesaving in patients who present with severe-grade sjambok injury and established AKI that is not responsive to intravenous fluid therapy

We hypothesise that the form of AKI in sjambok injuries is associated with an aerobic acidosis, while other forms of AKI in trauma are due to anaerobic conditions such as anaemia, hypotension and reperfusion, all of which have significant systemic effects, leading to multiple organ dysfunction. Supporting this hypothesis is the finding that all the patients presented with very mild lactate elevation (a marker of anaerobic metabolism), with no difference between patients with or without AKI. Future studies should be aimed at investigating this hypothesis.

Studies are also required to examine the outcomes of patients who develop high-grade AKI requiring RRT and compare them with other forms of trauma-induced AKI requiring RRT. The role of early dialysis in this form of injury also requires investigation.

\section{Conclusion}

The risk stratification score using VB proposed by Muckart et al. ${ }^{[5]}$ was shown to be valid in this study using the KDIGO risk stratification system, and can be simplified to use VB alone for risk stratification in the management of patients with sjambok injuries. BE performs well in predicting the need for RRT, with a value of $<-7.25 \mathrm{mmol} / \mathrm{L}$ indicating severe injury.

\section{Acknowledgements. None.}

Author contributions. DLS, GLL and DJJM: concept and protocol development; JB and GLL: data collection; DLS and BM: statistical analysis; DLS, GL, JB, BM and DJJM: writing, editing and final approval of article. Funding. None.

\section{Conflicts of interest. None.}

1. Bellomo R, Ronco C, Kellum JA, Mehta RL, Palevsky P, Acute Dialysis Quality Initiative workgroup. Acute renal failure - definition, outcome measures, animal models, fluid therapy and information technology needs: The Second International Consensus Conference of the Acute Dialysis Quality Initiative (ADQI) Group. Crit Care 2004;8:R204. http://dx.doi.org/10.1186/cc2872

2. Mehta RL, Kellum JA, Shah SV, et al. Acute Kidney Injury Network: Report of an initiative to improve outcomes in acute kidney injury. Crit Care 2007;11:R31. http://dx.doi.org/10.1186/cc5713

3. Khwaja A. KDIGO clinical practice guidelines for acute kidney injury. Nephron Clin Pract 2012;120:c179-c184. http://dx.doi.org/10.1159/000339789

. Muckart DJ, Abdool-Carrim AT. Pigment-induced nephropathy after sjambok injuries. S Afr J Surg 1991;29(1):21-24.

5. Muckart DJ, Moodley M, Naidu AG, Reddy AD, Meineke KR. Prediction of acute renal failure following soft-tissue injury using the venous bicarbonate concentration. J Trauma 1992;33(6):813-817. http://dx.doi.org/10.1097/00005373-199212000-00003

6. Smith WA, Hardcastle TC. A crushing experience: The spectrum and outcome of soft tissue injury and myonephropathic syndrome at an urban South African university hospital. Afr J Emerg Med and myonephropathic syndrome at an urban South African unive

7. De Meijer AR, Fikkers BG, de Keijzer MH, van Engelen BGM, Drenth JPH. Serum creatine kinase as predictor of clinical course in rhabdomyolysis: A 5-year intensive care survey. Intensive Care Med 2003;29(7):1121-1125. http://dx.doi.org/10.1007/s00134-003-1800-5 
8. McMahon GM, Zeng X, Waikar SS. A risk prediction score for kidney failure or mortality in rhabdomyolysis. JAMA Intern Med 2013;173(19):1821-1828. http://dx.doi.org/10.1001/ in rhabdomyolysis. JAMA

9. Simpson JP, Taylor A, Sudhan N, Menon DK, Lavinio A. Rhabdomyolysis and acute kidney injury: Creatine kinase as a prognostic marker and validation of the McMahon Score in a 10-year cohort: A retrospective observational evaluation. Eur J Anaesthesiol 2016;33(12):906-912. http://dx.doi. org/10.1097/EJA.0000000000000490

10. Skinner DL, Hardcastle TC, Rodseth RN, Muckart DJJ. The incidence and outcomes of acute kidney injury amongst patients admitted to a level I trauma unit. Injury 2014;45(1):259-264. http://dx.doi. org/10.1016/j.injury.2013.07.013

11. Bihorac A, Delano MJ, Schold JD, et al. Incidence, clinical predictors, genomics, and outcome of acute kidney injury among trauma patients. Ann Surg 2010;252(1):158-165. http://dx.doi.org/10.1097/ SLA.0b013e3181deb6bc
12. Podoll AS, Kozar R, Holcomb JB, Finkel KW. Incidence and outcome of early acute kidney injury in critically-ill trauma patients. PLoS One 2013;8(10):e77376. http://dx.doi.org/10.1371/journal. pone. 0077376

13. De Abreu K, Silva GB, Barreto A, Melo FM. Acute kidney injury after trauma: Prevalence, clinical characteristics and RIFLE classification. Indian J Crit Care Med 2010;14(3):121-128. http://dx.doi org $/ 10.4103 / 0972-5229.74170$

14. Baeza-Trinidad R, Brea-Hernando A, Morera-Rodriguez S, et al. Creatinine as predictor value of mortality and acute kidney injury in rhabdomyolysis. Intern Med J 2015;45(11):1173-1178. http:// dx.doi.org/10.1111/imj.1281

Accepted 11 January 2017. 